\title{
Cardiomyoplasty: Ventricular reconstruction after tumor resection
}

\author{
Juan-Carlos Chachques, MD, PhD \\ Pantelis G. Argyriadis, MD \\ Christian Latremouille, MD \\ Nicola D'Attellis, MD \\ Paul Fornes, MD \\ Patrick Bruneval, MD \\ Jean-Paul Couetil, MD \\ Alain F. Carpentier, MD, PhD
}

From the Department of Cardiovascular Surgery, Broussais and Pompidou Hospitals, Paris, France.

Received for publication May 14, 2001; revisions requested July 20, 2001; revisions received Sept 19, 2001; accepted for publication Oct 25, 2001.

Address for reprints: Juan C. Chachques, MD, PhD, Pompidou Hospital, 20, Rue Leblanc, 75015, Paris, France (E-mail: j.chachques@brs.ap-hop-paris.fr).

J Thorac Cardiovasc Surg 2002;123:889-94

Copyright $\odot 2002$ by The American Association for Thoracic Surgery

0022-5223/2002 \$35.00+0 $\quad \mathbf{1 2 / 1 / 1 2 1 4 9 3}$

doi:10.1067/mtc.2002.121493
Objective: Although cardiac transplantation has been performed for complete removal of ventricular tumors, complete surgical resection with ventricular reconstruction is desirable. Thus patients with benign tumors would probably be cured, and those with malignant tumors would have a better prognosis. In this study extensive and complete surgical resection of ventricular tumors is followed by anatomic and functional ventricular reconstruction with a dynamic cardiomyoplasty procedure.

Methods: Seven patients (mean age, 32.7 years) underwent complete resection of ventricular tumors. Histologic types were distributed as follows: fibroma in 2 patients and sarcoma, lymphosarcoma, hemangioma, lipoma, and metastatic angiosarcoma, respectively, in the remaining 5 patients. Six of the patients were considered candidates for heart transplantation because of the extent of tumor invasion. Surgery consisted of 4 steps: (1) tumor resection; (2) coronary artery resection (when invaded by the tumor) and coronary artery bypass grafting; (3) valvular reconstruction (when possible) or replacement; and (4) ventricular wall reconstruction with a pericardial patch for closure of the ventricular defect (neoendocardium) covered by the electrostimulated latissimus dorsi muscle flap (neomyocardium).

Results: All patients survived surgical intervention, but 2 late postoperative deaths are reported. Among the surviving patients, early complications played a major role in their postoperative course and consisted of arrhythmias, atrioventricular block necessitating a dual-chamber pulse generator, respiratory insufficiency, and heart failure. Two patients were assisted postoperatively with an intra-aortic balloon pump. On postoperative follow-up (mean, $72.4 \pm 8.5$ months), an improvement in the patients' functional status was observed. Patients moved from a mean New York Heart Association functional class of 2.8 to a mean functional class of 1.2.

Conclusions: The excellent long-term evolution without recurrence, ventricular dysfunction, and/or thromboembolic complications implies that cardiomyoplasty could be recommended as an alternative to heart transplantation for the therapy of large ventricular tumors.

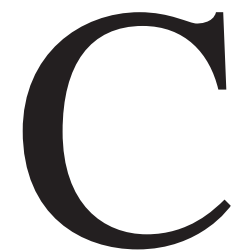

ardiac tumors are generally rare, with an incidence ranging from $0.0017 \%$ to $0.03 \%$ at postmortem examinations in different series. ${ }^{1}$ Ventricular tumors are distinctly rare, and of all primary tumors of the heart, those of ventricular origin represent fewer than $10 \% .^{2}$ Metastatic disease of the heart is far more common and has been found at autopsy in up to $21 \%$ of patients with cancer. Approximately $75 \%$ of primary cardiac tumors are benign, and $25 \%$ are malignant. 3,4 


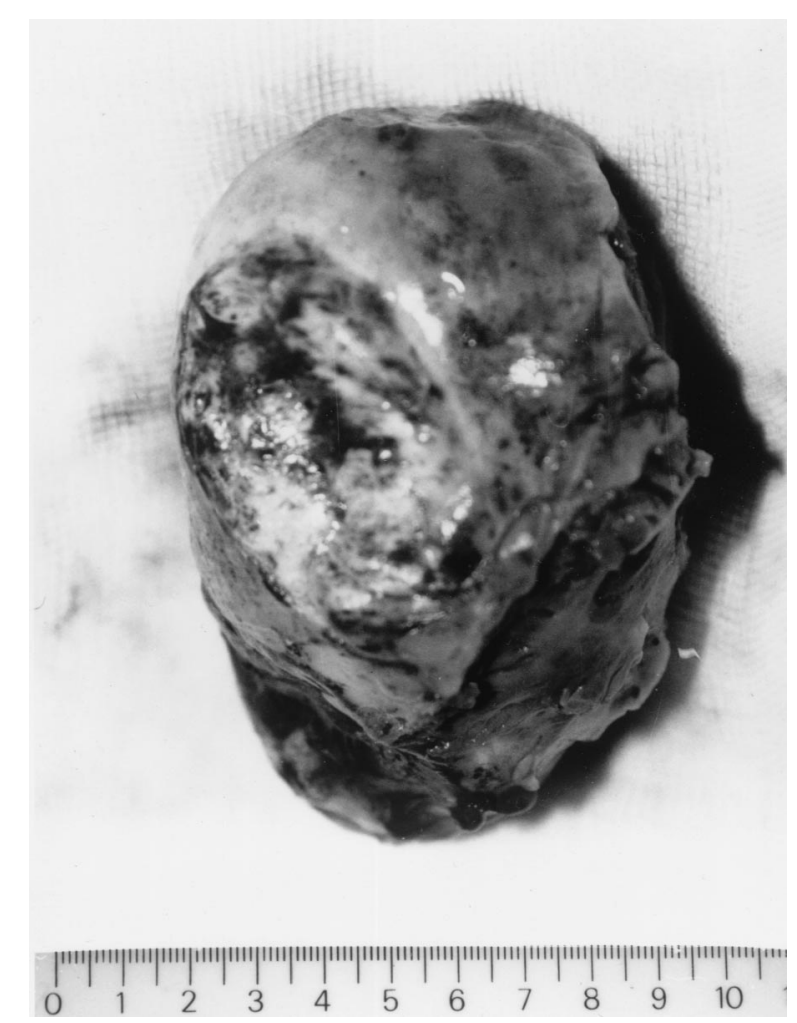

Figure 1. Macroscopic view of right ventricular fibroma requiring tricuspid valve annuloplasty, right coronary artery bypass, and cardiomyoplasty after resection (patient 3 ).

Although cardiac transplantation has been performed for complete removal of ventricular tumors, complete surgical resection with ventricular reconstruction is desirable, insofar as that patients with benign tumors would probably be cured, 5,6 whereas those with malignant tumors would have a better prognosis. In the following study, extensive and complete surgical resection of ventricular tumors was followed by anatomic ventricular reconstruction with a cardiomyoplasty procedure. Our clinical experience in 7 patients is presented with long-term follow-up from 3 to 15 years for the surgical treatment of ventricular tumors.

\section{Methods}

At the Department of Cardiac Surgery of Broussais Hospital, the medical records and diagnostic test results of 92 patients presenting with cardiac tumors between September 1985 and June 2000 were examined. Of these patients, 33 (18 women) had myxomas, and all of them were adults (mean age, $58.1 \pm 18.2$ years). Fifty-nine patients (33 women) had other types of tumors (mean age, $45.6 \pm 17.9$ years). Preoperative diagnosis was made by means of echocardiography, magnetic resonance imaging, angiography, and tumor biopsy. The presence or absence of metastases was generally assessed by means of computed tomography. Seven patients underwent complete resection of ventricular tumors, with anatomic reconstruction by means of dynamic cardiomyoplasty.
Six of these patients were considered candidates for heart transplantation because of the extent of the tumor invasion. All patients were followed up at our institution after hospital discharge. The group of patients undergoing resection followed by cardiomyoplastic reconstruction had a mean follow-up of 72.4 months.

\section{Patient Population}

Seven adult patients (4 women and 3 men; mean age, 32.7 years; age range, 22-55 years; mean weight, $66.9 \pm 10.17 \mathrm{~kg}$; mean height, $168 \pm 6.11 \mathrm{~cm}$ ) underwent tumor resection and the cardiomyoplasty procedure. The most common clinical symptoms were syncopal events, tachyarrhythmias, and heart failure. Cardiac tumors were primary in 6 patients, and metastatic disease in 1 patient. The distribution of histologic types was fibroma in 2 patients (Figure 1) and sarcoma, lymphosarcoma, hemangioma, lipoma, and metastatic angiosarcoma, respectively, in the remaining 5 patients (Table 1).

\section{Surgical Technique: Principles for Tumor Resection and Ventricular Reconstruction}

Tumor resection. The advantage of using the cardiomyoplasty approach after tumor resection is that the tumor can be extensively resected, including the borders, to avoid leaving atypical cells. During cardiopulmonary bypass, the resection includes normal myocardial tissue strong enough to suture a pericardial patch, so as to close the ventricular cavity. The complementary latissimus dorsi muscle (LDM) cardiomyoplasty restores myocardial function, preserving normal systolic and diastolic functions.

Coronary artery resection. If the main branches of the coronary arteries are involved by the tumor, the approach includes resection of a segment of the arteries. In all cases requiring coronary artery resection, postoperative coronary perfusion is ensured by a coronary artery bypass graft. If the coronary sinus is involved by the tumor, the feasibility of the tumor resection must be carefully evaluated.

Valvular resection or reconstruction. When the cardiac valves are invaded, our approach is to preserve both valvular and subvalvular structures whenever possible. In some cases of partial tumor invasion of the mitral or tricuspid valve, the leaflet may be excised from the anulus. Then the leaflets are reimplanted after tumor resection and reinforced with a prosthetic annuloplasty ring. When the valve is extensively invaded by a tumor, it should be replaced with a prosthetic valve.

Ventricular wall reconstruction. The residual defect resulting from tumor resection can be closed, maintaining an adequate residual ventricular chamber. The LDM flap is then used to cover this area, reenforcing the ventricular sutures (Figure 2). However, in most of the patients operated on by our group, the ventricular defects were very large. For these patients, the approach consisted of closing the ventricular cavity by using an autologous pericardial patch (immersed for 10 minutes in a $0.6 \%$ glutaraldehyde solution). The pericardial patch was fixed to the ventricular borders with a running Prolene 4-0 suture (Ethicon, Inc, Somerville, NJ), and the LDM flap was fixed over the residual myocardium and pericardial patch. In this manner an anatomic reconstruction was performed, with the pericardial patch representing the neoendocardium and the electrostimulated LDM representing the neomyocardium. An adequate ventricular cavity was preserved by using 


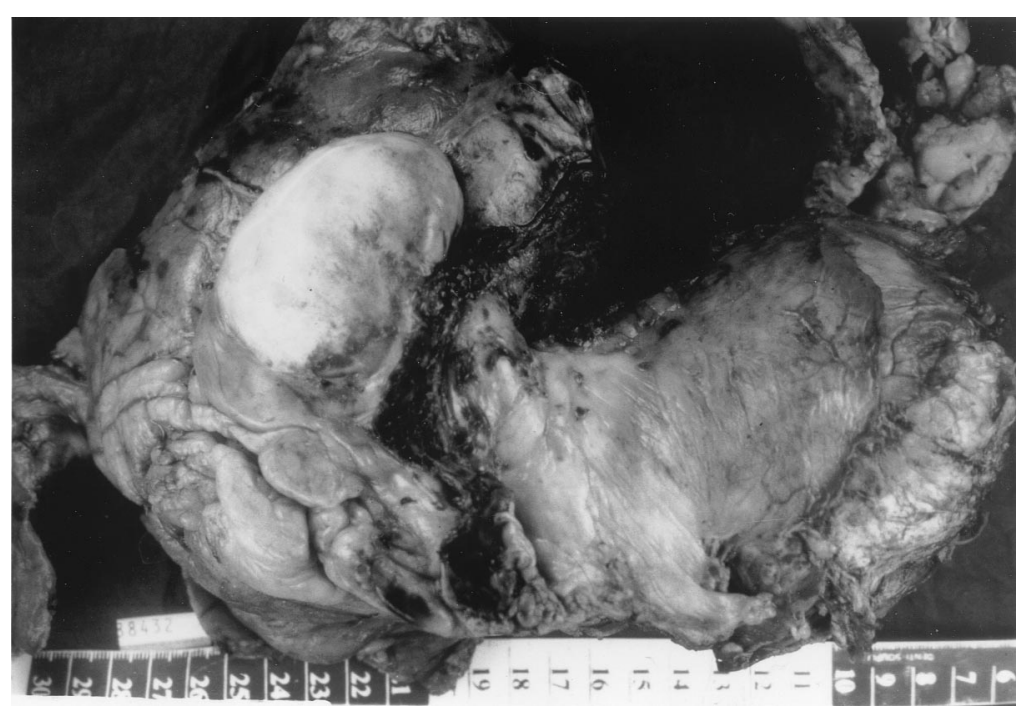

Figure 2. Fibroma weighing $1.4 \mathrm{~kg}$ invading the diaphragmatic wall of both ventricles (patient 1).

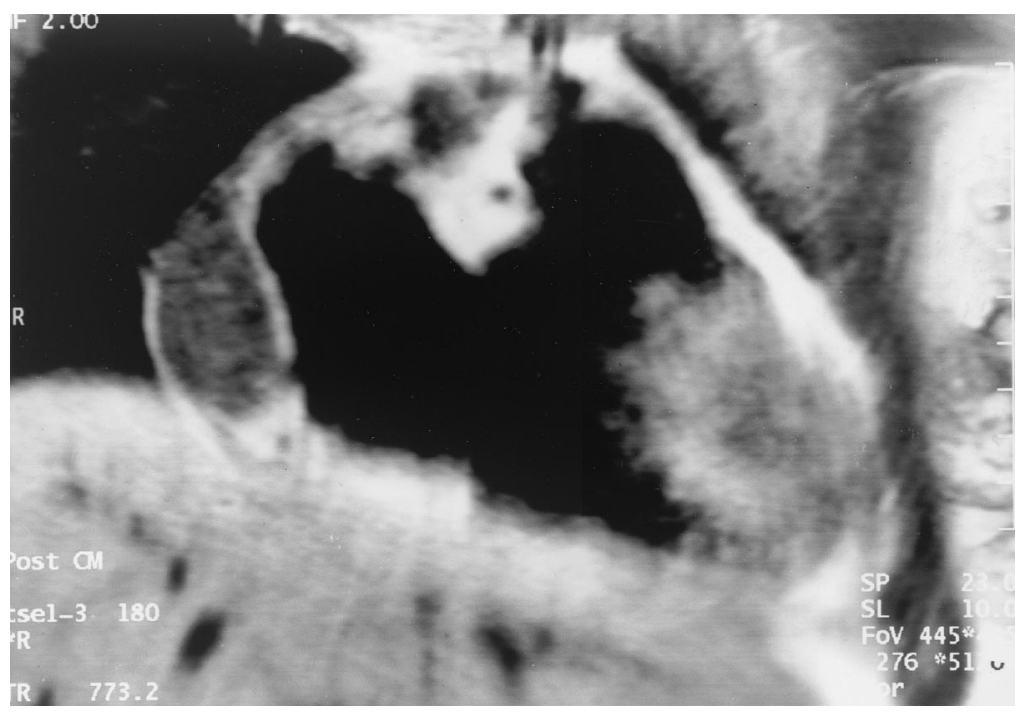

Figure 3. Magnetic resonance image showing the right ventricle infiltrated by an angiosarcoma in a 22-year-old woman (patient 7).

TABLE 1. Preoperative status

\begin{tabular}{|c|c|c|c|c|c|c|c|}
\hline $\begin{array}{l}\text { Patient } \\
\text { No. }\end{array}$ & $\begin{array}{l}\text { Age } \\
\text { (y) }\end{array}$ & Sex & $\begin{array}{c}\text { Weight } \\
\text { (kg) }\end{array}$ & $\begin{array}{c}\text { Height } \\
\text { (cm) }\end{array}$ & Histology & Origin & Symptoms \\
\hline 1 & 38 & $\mathrm{~F}$ & 62 & 165 & Fibroma & $\mathrm{LV}+\mathrm{RV}$ & $\mathrm{HF}$ \\
\hline 2 & 55 & $M$ & 78 & 170 & Lymphosarcoma & $\mathrm{RA}+\mathrm{RV}$ & $\mathrm{HF}+\mathrm{RI}$ \\
\hline 3 & 22 & $\mathrm{~F}$ & 53 & 161 & Fibroma & RV & VA \\
\hline 4 & 26 & $M$ & 80 & 176 & Hemangioma & VS & $\mathrm{HF}+\mathrm{VA}$ \\
\hline 5 & 38 & $M$ & 72 & 176 & Rhabdosarcoma & $\mathrm{RV}+\mathrm{VS}$ & $\mathrm{HF}$ \\
\hline 6 & 28 & $\mathrm{~F}$ & 58 & 163 & Lipoma & LV & PC \\
\hline 7 & 22 & $\mathrm{~F}$ & 65 & 165 & Angiosarcoma & $\mathrm{RA}+\mathrm{RV}$ & $\mathrm{HF}$ \\
\hline
\end{tabular}

$L V$, Left ventricle; $R V$, right ventricle; $H F$, heart failure; $R A$, right atrium; $R I$, respiratory insufficiency; $V A$, ventricular arrhythmias; $V S$, ventricular septum; $P C$, pain in the chest. 


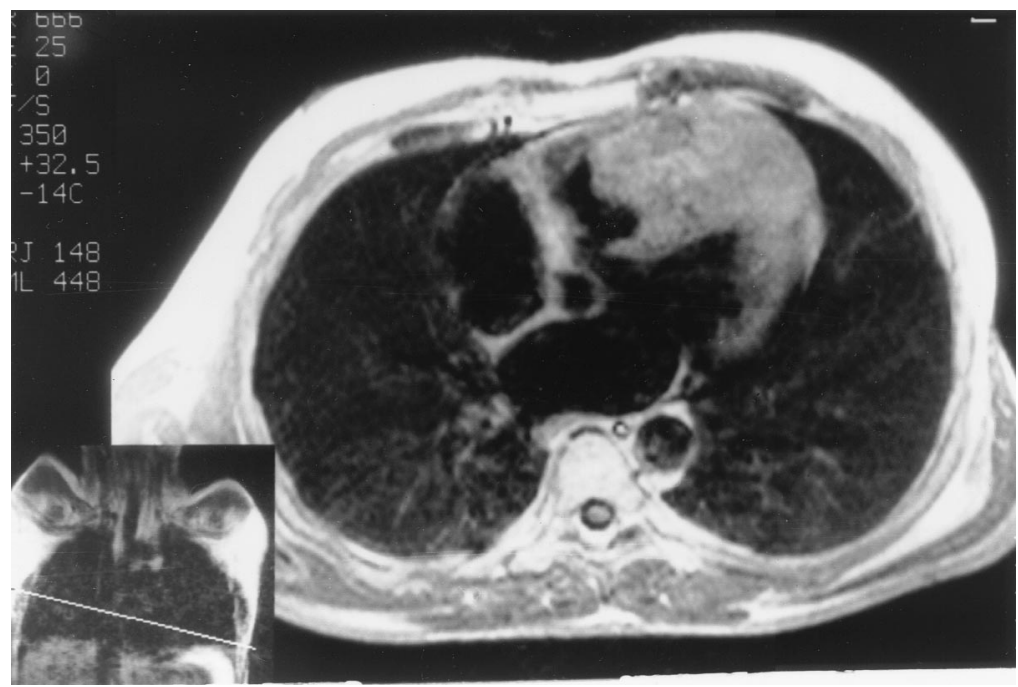

Figure 4. Electron beam scanner showing the invasion of the ventricular septum and right ventricular wall by a rhabdosarcoma (patient 5).

TABLE 2. Surgical procedures

\begin{tabular}{llc}
\hline Excision & $\begin{array}{c}\text { Ventricular } \\
\text { reconstruction }\end{array}$ & Associated procedures \\
\hline Complete & CMP & Diaphragm plasty \\
Complete & CMP + PP & TV plasty + PDA bypass \\
Complete & CMP + PP & TV plasty + PA \\
& & plasty + PDA bypass \\
Complete & CMP + PP & TV plasty + VSD \\
& & repair + AV pacemaker \\
Complete & CMP + PP & VSD repair \\
Complete & CMP + PP & MV replacement \\
Incomplete & CMP + PP & TV replacement + PDA \\
& & bypass \\
\hline
\end{tabular}

$C M P$, Cardiomyoplasty; $P P$, pericardial patch; $T V$, tricuspid valve; $P D A$, posterior descending artery; $P A$, pulmonary artery; $A V$, atrioventricular; $V S D$, ventricular septal defect; $M V$, mitral valve.

this technique. A pulse train generator (Cardio-Myostimulator; Medtronic, Minneapolis, Minn) was used to deliver synchronous systolic pulses by means of left ventricular electrodes connected to the sensing pacemaker chamber and 2 latissimus dorsi intramuscular electrodes coupled to the pacing chamber. The LDM electrostimulation started at postoperative week 2 . After 2 months, the patients were stimulated with a 6-pulse burst and a heart/muscle ratio of $2: 1$.

\section{Associated Surgical Procedures}

All patients underwent combined surgical procedures because of the extensive and invasive nature of the tumors. These procedures included tricuspid valve annuloplasty or replacement, mitral valve replacement, posterior descending coronary artery bypass grafting, pulmonary valve annuloplasty, reconstruction of septal defects, and atrioventricular pacemaker implantation (Tables 2 and 3).

\section{Results}

All patients survived surgical intervention, but 2 late postoperative deaths occurred. The first patient, given a diagnosis of lymphoma, died on postoperative day 45 as a result of sepsis. The second patient, with a sarcoma, died on postoperative day 8 because of aortic bleeding originating from a portion of the aorta invaded by the tumor. The 5 survivors could benefit from a complete resection of the ventricular tumors confirmed by means of histopathologic studies. The margins of the resected myocardium were free of tumor cells. Among the surviving patients, early complications played a major role during their postoperative course and consisted of arrhythmia, atrioventricular block necessitating a dual-chamber pulse generator, respiratory insufficiency, and heart failure. Two patients were assisted postoperatively with an intra-aortic balloon pump. Patients 5 and 7 underwent preoperative chemotherapy, and patient 5 was followed up with postoperative chemotherapy. In patient 7 residual tumor cells were observed in histologic studies. This patient died on postoperative day 8 (Figure 3). On follow-up (mean of 72.4 months postoperatively), an improvement in the patients' functional status was observed. Patients moved from preoperative New York Heart Association functional class II to IV (mean, 2.8) to postoperative functional class I (mean, 1.2), with attenuation of symptoms. No thromboembolic complications were observed. Clinical follow-up, adjuvant therapy, and tumor recurrence are included in Table 4.

\section{Discussion}

The prognosis of patients with primary malignant cardiac tumors is dismal, with death occurring within 6 months regardless of the histologic diagnosis. ${ }^{5,7}$ The treatment of 
TABLE 3. Tumor dimensions and ventricular function

\begin{tabular}{|c|c|c|c|c|c|c|}
\hline Patient & $\begin{array}{c}\text { Tumor } \\
\text { dimensions } \\
\text { (cm) }\end{array}$ & Patch size $(\mathrm{cm})$ & $\begin{array}{c}\text { Preoperative } \\
\text { LVEF }(\%)\end{array}$ & $\begin{array}{c}\text { Postoperative } \\
\text { LVEF (\%) }\end{array}$ & $\begin{array}{c}\text { Preoperative } \\
\text { RVEF (\%) }\end{array}$ & $\begin{array}{c}\text { Postoperative } \\
\text { RVEF (\%) }\end{array}$ \\
\hline 1 & $28 \times 20 \times 10$ & $\begin{array}{c}\text { No patch (endocardium } \\
\text { preserved) }\end{array}$ & 23 & 38 & 20 & 27 \\
\hline 2 & $9 \times 7 \times 5$ & $5 \times 4$ & 37 & $*$ & 15 & $*$ \\
\hline 3 & $7 \times 7 \times 7$ & $5 \times 5$ & 40 & 55 & 10 & 32 \\
\hline 4 & $6 \times 6 \times 6$ & $4 \times 3$ & 28 & 64 & 25 & 37 \\
\hline 5 & $8 \times 9 \times 4$ & $6 \times 5$ & 44 & 54 & 26 & 35 \\
\hline 6 & $8 \times 5 \times 3$ & $6 \times 4$ & 48 & 56 & 21 & 32 \\
\hline 7 & $13 \times 8 \times 7$ & $7 \times 6$ & 58 & $\dagger$ & 16 & $\dagger$ \\
\hline
\end{tabular}

Normal values measured with MUGA scan: left ventricle, greater than $50 \%$; right ventricle, greater than $30 \%$. LVEF, Left ventricular ejection fraction; RVEF, right ventricular ejection fraction.

*Patient died at postoperative month 2

†Patient died at postoperative week 2.

primary malignant cardiac tumors is complex and difficult because of the aggressive biologic characteristics of these tumors and the limited experience of any one center in the management of these lesions. ${ }^{5}$ Bear and Moodie ${ }^{8}$ reviewed 11 patients with malignant cardiac tumors, 10 of whom had died at the time of their report, with an average of 9 months from the time of diagnosis to death. Putnam and associates ${ }^{9}$ demonstrate no significant difference in survival of patients with primary malignant sarcomas of the heart who underwent surgical intervention alone compared with those who had adjuvant postoperative chemotherapy.

According to Murphy and coworkers, ${ }^{1}$ patients who have potentially resectable disease are rare. They described 12 patients with primary cardiac sarcomas of a total of 114 patients with primary tumors of the heart. Survival was 9 months, but palliation was good. Most patients died of metastatic disease. Beghetti and colleagues ${ }^{10}$ believe that if total excision is not possible, partial resection may be beneficial. They report a case of an infant who underwent partial excision of a fibroma and creation of a bidirectional cavopulmonary shunt. Jamieson and associates ${ }^{11}$ have reported transplantation in a 17-year-old patient with an unresectable left ventricular fibroma, whereas Aravot and coworkers ${ }^{12}$ described a patient who did well 5 years after orthotopic transplantation for a neurofibrosarcoma of the heart. The actual number of primary cardiac tumors is small, and the number that are treatable by means of orthotopic transplantation is even smaller. ${ }^{13,14}$ Reece and colleagues ${ }^{6}$ described 20 patients who underwent surgery at the Texas Heart Institute for primary tumors other than myxomas. This series confirms the poor results obtained with primary malignant cardiac tumors and indicates that metastases usually cause death within a year.

Concerning benign cardiac tumors, the diagnosis in many cases is achieved when the tumor mass is large, producing malignant arrhythmias and hemodynamic decom-
TABLE 4. Adjuvant tumoral therapy and clinical follow-up

\begin{tabular}{llrrl}
\hline Patient & Adjuvant therapy & $\begin{array}{c}\text { Follow-up } \\
\text { (mo) }\end{array}$ & NYHA FC & \multicolumn{1}{c}{ Clinical status } \\
\hline 1 & Antiarrhythmics & 181 & I & Full active \\
2 & - & - & - & Died \\
3 & - & 109 & I & Delivered 2 babies \\
4 & Cardiac pacing & 99 & I & Full active \\
5 & Chemotherapy & 75 & II & Asymptomatic \\
6 & - & 46 & I & Full active (athletics) \\
7 & Chemotherapy & - & - & Died \\
\hline
\end{tabular}

$F C$, Functional class.

pensation. ${ }^{15}$ At this stage, surgical resection may be difficult and followed by hemodynamic decompensation because of the small ventricular chambers, resulting from the resection and ventricular closure.

The role of cardiomyoplasty in patients with large ventricular tumors is based on the principle that this procedure offers the possibility of reconstructing a contractile ventricular wall, thus preserving an adequate size and shape of the ventricular residual cavities. Moreover, in malignant tumors this technique allows a large resection of the disease without recurrence, avoiding heart transplantation (Figure 4).

In our institution we selected only 7 patients from a series of 59 patients (excluding 33 myxomas) to perform cardiomyoplasty after cardiac tumor resection. In our experience the size and localization of these tumors and the estimated residual ventricular volumes would result in a difficult operative and postoperative problem, with high risk for anatomic and functional complications.

Clinical limits for the indication of cardiomyoplasty in patients presenting with ventricular tumors would be the invasion of the coronary sinus, as well as more than $50 \%$ of the ventricular chambers. Extensive invasion of the ventricular septum should also be an exclusion criteria for cardio- 
myoplasty because the role of the ventricular septum is of capital importance for cardiomyoplasty. Physiologically, the newly reconstructed ventricular wall is hemodynamically integrated with a still active ventricular septum. In patients with malignant tumors, regression of tumoral volume in response to alternative or adjuvant therapies to surgical intervention (chemotherapy or radiotherapy) should be carefully evaluated before cardiomyoplasty.

Latissimus dorsi dynamic cardiomyoplasty has been performed worldwide in more than 1500 patients. ${ }^{16}$ Most of the indications include patients with ischemic (50\%) and idiopathic cardiomyopathies (50\%). We found that cardiomyoplasty is well adapted to reconstruct the ventricular chambers after tumor resection. ${ }^{16-18}$ Historically, it was necessary to adapt this technique for this disease. ${ }^{18}$ In this manner the rationale was to create a new ventricular wall by using autologous pericardium to replace the endocardium, taking advantage of its hemocompatibility. The electrostimulated LDM was used to replace the resected myocardium. Our surgical approach to reconstruct ventricular chambers after tumor resection is to preserve a maximum of the anatomic and functional characteristics of each ventricle, including the valvular apparatus and a compliant ventricular chamber. The excellent long-term evolution without recurrence, ventricular dysfunction, and/or thromboembolic complications implies that cardiomyoplasty could be recommended as an alternative to heart transplantation for therapy of large ventricular tumors.

We thank Theano Irinopoulou, $\mathrm{PhD}$, for her assistance in the statistical analysis of our data.

\section{References}

1. Murphy MC, Sweeny MS, Putnam JB Jr, et al. Surgical treatment of cardiac tumors: 25-year experience. Ann Thorac Surg. 1990;49:612-7.
2. Dietl CA, Torres AR, Favaloro RG. Ventricular tumors: surgical options. Cardiovasc Surg. 1993;1:632-7.

3. Miralles A, Bracamonte L, Soncul H. Cardiac tumors: clinical experience and surgical results in 74 patients. Ann Thorac Surg. 1991;52: 886-95.

4. Larrieu AJ, Jamieson WR, Tyers GF, et al. Primary cardiac tumors: experience with 25 cases. J Thorac Cardiovasc Surg. 1982;83:339-48.

5. Dein JR, Frist WH, Stinson EB, et al. Primary cardiac neoplasms. Early and late results of surgical treatment in 42 patients. $J$ Thorac Cardiovasc Surg. 1987;93:502-11.

6. Reece IJ, Cooley DA, Frazier OH, Hallman GL, Powers PL, Monteno CG. Cardiac tumors: clinical spectrum and prognosis of lesions other than classical benign myxoma in 20 patients. $J$ Thorac Cardiovasc Surg. 1984;88:439-46.

7. Poole GV, Meredith JW, Breyer RH, Mills SA. Surgical implications in malignant cardiac disease. Ann Thorac Surg. 1983;36:484-91.

8. Bear PA, Moodie DS. Malignant primary cardiac tumors: the Cleveland Clinic experience-1956-1986. Chest. 1987;92:860-2.

9. Putnam JB Jr, Sweeny MS, Colon R, et al. Primary cardiac sarcomas. Ann Thorac Surg. 1991;51:906-10.

10. Beghetti M, Haney I, Williams WG, Mawson J, Freedom RM, Gow RM. Massive right ventricular fibroma treated with partial resection and a cavopulmonary shunt. Ann Thorac Surg. 1996;62:882-4.

11. Jamieson SW, Gaudiani VA, Reitz BA, et al. Operative treatment of an unresectable tumor of the left ventricle. J Thorac Cardiovasc Surg. 1981;81:797-9.

12. Aravot DJ, Baner NR, Madden B, et al. Primary cardiac tumors-is there a place for cardiac transplantation? Eur J Cardiothorac Surg. 1989;3:521-4.

13. Valente M, Cocco P, Thiene G, et al. Cardiac fibroma and heart transplantation. J Thorac Cardiovasc Surg. 1993;106:1208-12.

14. Aufiero TX, Pae WE, Clemson BS, Pawlush DG, Davis D. Heart transplantation for tumor. Ann Thorac Surg. 1993;56:1174-6.

15. Chitwood WR Jr. Cardiac neoplasms: current diagnosis, pathology and therapy. J Card Surg. 1988;3:119-54.

16. Chachques JC, Berrebi A, Carpentier A, et al. Study of muscular and ventricular function in dynamic cardiomyoplasty: a ten-year followup. J Heart Lung Transplant. 1997;16:854-68.

17. Grinda JM, Chachques JC, Jouan J, Latremouille C, Deloche A, Carpentier AF. Left ventricular reconstruction after resection of a large fibroma. Ann Thorac Surg. 2001;71:1354-6.

18. Carpentier A, Chachques JC. Myocardial substitution with a stimulated skeletal muscle: first successful clinical case. Lancet. 1985;1: 1267.

\section{Authoritative}

The Journal of Thoracic and Cardiovascular Surgery is the most frequently cited thoracic/cardiovascular surgery journal in the Science Citation Index. An article in JTCVS is sited on average almost twice as often as those in the closest cardiothoracic journal. 